University of Nebraska - Lincoln

DigitalCommons@University of Nebraska - Lincoln

\title{
3-2013
}

\section{Parasitoid Infestation Changes Female Mating Preferences}

Oliver M. Beckers

Indiana University - Bloomington, obeckers@indiana.edu

William E. Wagner

University of Nebraska-Lincoln, wwagner1@unl.edu

Follow this and additional works at: https://digitalcommons.unl.edu/bioscifacpub

Part of the Behavior and Ethology Commons, and the Entomology Commons

Beckers, Oliver M. and Wagner, William E., "Parasitoid Infestation Changes Female Mating Preferences" (2013). Faculty Publications in the Biological Sciences. 241.

https://digitalcommons.unl.edu/bioscifacpub/241

This Article is brought to you for free and open access by the Papers in the Biological Sciences at DigitalCommons@University of Nebraska - Lincoln. It has been accepted for inclusion in Faculty Publications in the Biological Sciences by an authorized administrator of DigitalCommons@University of Nebraska - Lincoln. 


\title{
Parasitoid Infestation Changes Female Mating Preferences
}

\author{
Oliver M. Beckers ${ }^{1,2}$ and William E. Wagner, Jr. ${ }^{2}$ \\ 1. School of Biological Sciences, University of Nebraska-Lincoln, Nebraska, USA \\ 2. Department of Biology, Indiana University, Bloomington, Indiana, USA \\ Corresponding author - O. M. Beckers, obeckers@indiana.edu
}

\begin{abstract}
Females often adjust their mating preference to environmental and social conditions. This plasticity of preference can be adaptive for females and can have important consequences for the evolution of male traits. While predation and parasitism are widespread, their effects on female preferences have rarely been investigated. Females of the cricket Gryllus lineaticeps are parasitized by the parasitoid fly Ormia ochracea. Infestation with fly larvae substantially reduces female life span and thus reproductive opportunities of the cricket. Both female G. lineaticeps and flies orient to male song and both prefer male songs with faster chirp rates to songs with slower chirp rates. We tested the effect of parasitic infestation on female responsiveness to male song and female chirp rate preferences. The proportion of individuals responding to male songs did not differ between infested and control females. Control females preferred intermediate chirp rates to slow chirp rates and did not discriminate between fast and intermediate chirp rates. In contrast, infested females showed no preferences in the choice trials, indicating reduced chirp rate selectivity. This plasticity in female preferences may be adaptive; parasitized females may have a higher probability of reproducing before they are killed by the parasitoids if they are less selective (i.e. there will be a larger pool of males considered acceptable). The change in preferences suggests relaxed selection on male chirp rate during times of parasitism.
\end{abstract}

Keywords: Female preference, Gryllus lineaticeps, Ormia ochracea, Phenotypic plasticity, Sexual selection

F emale mating preferences often show substantial plasticity and change in response to a variety of biotic environmental factors, such as predation (e.g. Hedrick \& Dill 1993; Godin \& Briggs 1995; Gong \& Gibson 1996; Johnson \& Basolo 2003), parasitism (e.g. Zuk et al. 1990; Poulin 1994; Cordoba-Aguilar et al. 2003) or social experience (e.g. Wagner et al. 2001b; Hebets 2003; King et al. 2003). Because plasticity in female preferences can change the strength and direction of sexual selection, it can have important ramifications for the evolution of sexually selected male traits (Poulin \& Vickery 1996; Rolff 1998; Cotton et al. 2006). For example, a reduction in selectivity allows males that usually are rejected by females to obtain matings under some environmental conditions, which may help to maintain genetic and phenotypic variation of male sexually selected traits (Chaine \& Lyon 2008).

The effect of parasitism on female preferences is particularly understudied, despite evidence that parasitism can have major effects on host reproduction and behavior. For example, parasitic infestation may cause sex-role reversals (Simmons 1994) and changes in reproductive patterns and behavior (e.g. Baudoin 1975; Ritchie \& Høeg 1981; Rupp 1996; Zakikhani \& Rau 1999; Beckers \& Wagner 2011b) and in nonreproductive behavior (e.g. Moore 1995; Libersat et al. 2009). Some studies have also shown that parasitism can affect female mate sam- pling (Buchholz 2004) and mate choice (Poulin \& Vickery 1996; Cordoba-Aguilar et al. 2003; Mazzi 2004). Even though parasitism and predation are prevalent in many taxa, parasite or predator-mediated changes in male traits, and especially female preferences for those traits, have received relatively little attention in studies of animal behavior (Poulin 1994).

Males of the variable field cricket, Gryllus lineaticeps, produce songs to attract females for mating. Females typically prefer males that produce songs with faster chirp rates (Wagner 1996), although they discriminate more strongly between low and intermediate chirp rates than between intermediate and high chirp rates (Wagner \& Basolo 2007a; Beckers \& Wagner 2011a). Males that produce faster chirp rates provide direct benefits to females that increase female fecundity and fertility in low nutrition environments (Wagner \& Harper 2003; Tolle \& Wagner 2011). Male calling song, however, not only attracts conspecific females, but also a parasitoid fly, Ormia ochracea, which deposits about 3 larvae on and 7 larvae around the male (Adamo et al. 1995a). Males are infested by larvae deposited directly on their body (Cade 1975). Silent females can be infested in a more indirect fashion: females that approach a singing male for mating may pick up the sticky larvae deposited around the male (sensu Cade 1975; Martin \& Wagner 2010), or they may be infested if they are in close proximity to 
the male when he is attacked by the parasitoid fly. In the field, infestation rates of G. lineaticeps can be as high as $60 \%$ for males and 6\% for females (Martin \& Wagner 2010). Infestation is typically always lethal for the host, and the host dies within 7-10 days of infestation (Adamo et al. 1995b; Beckers \& Wagner 2011b). Infested males substantially reduce their singing within 1 day after infestation (Beckers \& Wagner 2011b). In other species of Gryllus, females that were infested with O. ochracea larvae showed reduced reproductive behaviour (e.g. reduced tendency to mount males, rapid decline in egg laying) beginning at 3 days after infestation (Adamo et al. 1995b). Female field crickets typically become receptive to mating around 7 days of adult age and have a maximum natural adult life span of about 28 days (Murray \& Cade 1995). Because G. lineaticeps females mate with many males throughout their lives (Wagner et al. 2001a, 2007) and reproductive activities begin to decline 3 days following parasitism (Adamo et al. 1995b), infestation can substantially reduce female lifetime reproductive success, particularly for young and intermediate-aged females.

We tested the effect of infestation by $O$. ochracea larvae on female responsiveness to male song and female chirp rate preferences in G. lineaticeps. We hypothesized that parasitized females would show adaptive phenotypic plasticity in reproductive behavior by increasing their responsiveness to male song and/or expressing weaker chirp rate preferences. Both changes in behavior should lead to an increase in the probability that a parasitized female will find an acceptable mate and thus reproduce before dying. However, other outcomes for female responsiveness and chirp rate preferences are possible. For example, reduced responsiveness to male song may suggest parasitic manipulation. By preventing the host from reproducing, parasitoid larvae may force the host to save energy that the larvae could use for their own development, and reduce the risk of predation or superparasitism (i.e. infestation of a previously infested host by a member of the same parasite species; sensu van Dijken \& Waage 1987). Similarly, reduced responsiveness to male song may be a byproduct of infestation (i.e. sick females may not behave like healthy gravid females). As with the adaptive plasticity hypothesis, the parasitic manipulation and byproduct hypotheses predict that parasitized females will be less selective. First, high selectivity would prolong female mate searching, which would reduce the host's energy reserves and increases exposure to predators and parasites, which could be detrimental to the larvae. Second, sick females might be less selective because they have fewer resources to devote to sampling males.

\section{Methods}

\section{Animals}

We collected adult female O. ochracea at Rancho Sierra Vista in the Santa Monica Mountain National Recreation Area (near Newberry Park, California, U.S.A.) in the summer of 2011, using broadcasts of G. lineaticeps song (Wagner \& Basolo 2007b; Beckers \& Wagner 2011b, 2012a). We collected adult female G. lineaticeps from Cayucos, California $\left(35^{\circ} 28^{\prime} 023.16^{\prime \prime} \mathrm{N}\right.$, $120^{\circ} 52^{\prime} 016.68^{\prime \prime} \mathrm{W}$ ) in the summers of 2008 and 2009 to establish laboratory populations. The fly O. ochracea uses this population of G. lineaticeps as hosts for its larvae (Beckers \& Wagner 2012b). We brought flies and crickets to the University of Nebraska-Lincoln for the experiments. Most of the female crickets mated with males in the field and laid fertilized eggs in the laboratory. The offspring of the field-collected females constituted the first laboratory generation. We actively managed pairings between males and females for subsequent laboratory generations to reduce inbreeding (Beckers \& Wagner 2011a). We used females of the second and older laboratory genera- tions in our experiments (for rearing protocols see Beckers \& Wagner 2011a).

\section{Infestations}

Female crickets were reared to adulthood and placed in individual containers. Since female crickets are silent, larval infestation of females most likely occurs either when the female is close to the male as the parasitoid fly attacks the male, or when the female approaches the male for mating and picks up the larvae deposited around the male by the fly. Infestation of females is strongly linked to mating with a male (i.e. virgin females are unlikely to be parasitized). In addition, female G. lineaticeps mate with many males throughout their lives (Wagner et al. 2001a, 2007). To simulate the natural course of parasitism (parasitism of mated females), we paired each of our experimental females with one male prior to infestation or 'mock-infestation' (see below). Females were paired with a male 7-17 days after eclosion, and the duration of the pairing was $48 \mathrm{~h}$. On the day that males were removed from the container, we infested approximately half of the females with two fly larvae. To obtain the larvae, we killed a fly, dissected its abdomen and removed live planidia larvae for infestation. We deposited the larvae on the membranous area between head and thorax (Vincent \& Bertram 2009) using a probe (for details of infestations see Beckers \& Wagner 2011b). The remaining females were mock-infested (i.e. treated exactly the same way as the infested females except that we did not place larvae on the tip of the probe). Two days after infestation or mock-infestation, we tested female chirp rate preferences. Our research adhered to the ASAB/ABS guidelines for the use of animals in research, the legal requirements of the U.S.A., and all guidelines of the University of Nebraska.

\section{Experimental Set-up and Protocol}

Females from each treatment group were tested once in one of two choice experiments: (1) slow chirp rate $(1.8$ chirps/s) versus intermediate chirp rate (3.0 chirps/s), or (2) intermediate chirp rate $(3.0 \mathrm{chirps} / \mathrm{s})$ versus fast chirp rate $(4.2$ chirps/s). These chirp rates approximately cover the natural chirp rate range (mean $\pm 2 \mathrm{SD}$ ) of male G. lineaticeps songs (Wagner \& Reiser 2000; Wagner \& Basolo 2007a). Note that preferences for faster chip rates are strongest at the slow-to-intermediate chirp rate range, and females discriminate less strongly between faster chirp rates (Beckers \& Wagner 2011a; Wagner \& Basolo 2007a). Thus, we expected females to express preferences in the choice test with the slow and intermediate chirp rates rather than in the choice test with the intermediate and fast rates. A given female was only tested with one pair of stimuli. All stimuli were identical in all other song parameters except for the chirp interval (the period of silence between chirps), which was manipulated to generate stimuli that varied in chirp rate (for details see Wagner \& Basolo 2007a, b). All stimulus parameters corresponded to natural song values. Each stimulus was calibrated to a peak amplitude of 70 $\pm 1 \mathrm{~dB}$ SPL (re: $20 \mu \mathrm{Pa}$ ) at a distance of $30.5 \mathrm{~cm}$ from the loudspeaker. The infested females used in the two chirp rate trials were drawn from 11 and 14 full-sibling families. The control females used in each of the two chirp rate trials were drawn from 12 and 13 full-sibling families. No more than three females from the same family were included in any chirp rate trial. Linear mixed models that included family as a random effect showed that family had no effect on female responsiveness or choices. Family was therefore excluded from further analysis.

We conducted choice trials with female G. lineaticeps on the floor of a semianechoic chamber. We used a video camera inside the chamber and a monitor outside the chamber to ob- 
serve female choices (for details see Beckers \& Wagner 2011a). The floor of the test arena measured $2.2 \times 2.2 \mathrm{~m}$. We placed loudspeakers in the centre of loudspeaker circles (radius $=26$ $\mathrm{cm}$ ) in opposite corners of the arena floor. At the beginning of each trial, we placed a female cricket under a cup (radius $=$ $4 \mathrm{~cm}$ ) inside a release circle (radius $=5 \mathrm{~cm}$ ) in the centre of the arena, equidistant $(1.14 \mathrm{~m})$ to each loudspeaker. We acclimatized each female to the test stimulus combination for 5 min. We then released the female and determined which loudspeaker circle the female entered first. Trials in which the female did not leave the release circle within $10 \mathrm{~min}$ after lifting the cup, or did not enter a circle within $10 \mathrm{~min}$ after leaving the release circle, were terminated. The females in these trials were scored as unresponsive and no choice was noted. We switched stimulus pairs and loudspeaker broadcasts between successful trials. Experiments were conducted at an ambient temperature of $23.5 \pm 1{ }^{\circ} \mathrm{C}$, which falls within the natural range of temperatures experienced by the crickets at sunset in the field (O.M. Beckers, personal observation).

Mean SE adult age of females in each treatment when tested were as follows: infested, slow versus intermediate chirp rate: $13.78 \pm 0.48$ days $(N=27)$; infested, intermediate versus fast chirp rate: $13.89 \pm 0.47$ days $(N=27)$; control, slow versus intermediate chirp rate $=14.60 \pm 0.54$ days $(N=25)$; and control, intermediate versus fast chirp rate $=15.23 \pm 0.82$ days $(N=22)$. At least one larva emerged from all but one of the infested females, and females from which larvae emerged died within 3 days after larval emergence. One female assigned to the infestation treatment showed no evidence of larval infestation and was excluded from the analyses.

\section{Statistical Procedures}

We used logistic regressions to analyse the effect of larvae infestation on female responsiveness and chirp rate preference. We compared female responsiveness (whether females responded to the song broadcasts, i.e. entered one of the two loudspeaker circles) and preference (the chirp rate chosen in the trial if the female responded) between infested and control females. We conducted separate analyses for each type of choice test (slow versus intermediate and intermediate versus fast chirp rates). These models had several fixed effects: treatment (infested or noninfested), test temperature and female mass (measured on the day of the preference test). Since female age had no significant effect on female responsiveness or choices, we excluded age from further analysis. All statistical analyses were performed using the software package STATA v.10.

\section{Results}

First, we examined the effect of parasitism on female responsiveness to male mating songs. There was no effect of infestation treatment on female responsiveness in either preference trial (logistic regressions: slow versus intermediate chirp rate: $Z=0.52, N=52, P=0.603$; intermediate versus fast chirp rate: $N=49, Z=0.39, P=0.695$; Figure 1 ). Female mass negatively affected female responsiveness in the intermediate versus fast chirp rate trial $(Z=-3.29, N=49, P=0.001)$; that is, heavier females were less likely to respond. However, mass did not affect female responsiveness in the slow versus intermediate chirp rate trial $(Z=-0.79, N=52, P=0.427)$. Ambient temperature had no significant effect on female responsiveness in either trial (slow versus intermediate chirp rate: $Z=-0.84, N=$ $52, P=0.403$; intermediate versus fast chirp rate: $Z=0.88, N=$ $49, P=0.380)$.

Second, we examined the effect of parasitism on female chirp rate preferences. Female preferences were significantly

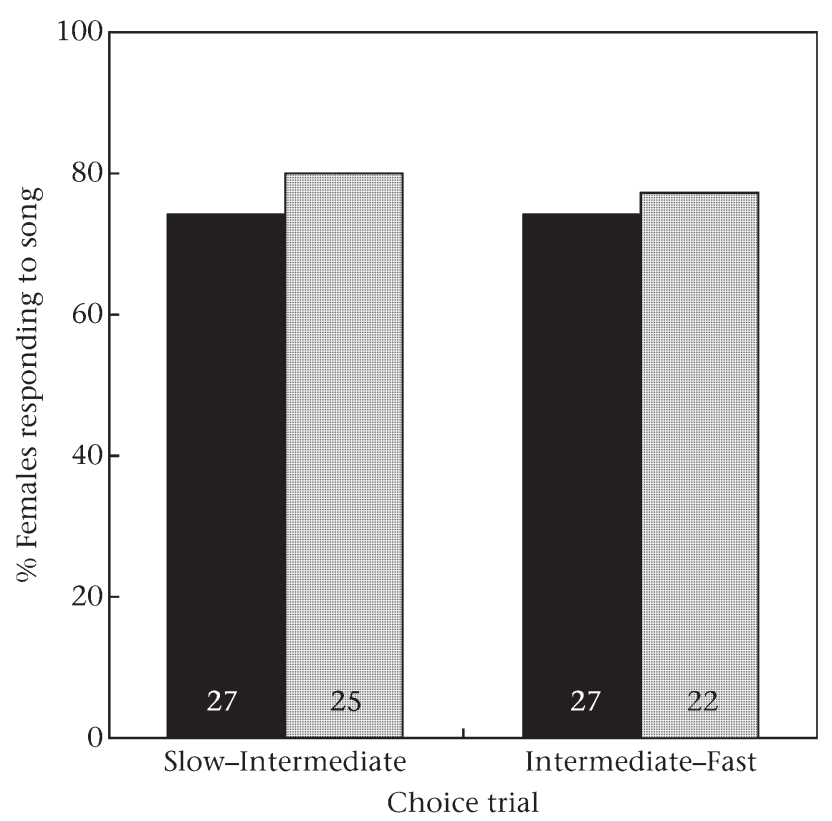

Figure 1. Percentage of infested (black bars) and control (grey bars) female field crickets, Gryllus lineaticeps, that responded to male mating song. Female responsiveness to slow (1.8 chirps/s) versus intermediate (3.0 chirps/s) chirp rates (left panel) and intermediate (3.0 chirps/s) versus fast (4.2 chirp/s) chirp rates (right panel). Number of females $(N)$ tested in each trial is indicated at the bottom of each bar.

affected by parasitism status in the slow versus intermediate chirp rate trial (logistic regression: $Z=2.06, N=40, P=0.039$; Figure 2). Control females more often chose the intermediate chirp rate song than the slow chirp rate song, whereas infested females were equally likely to choose the intermediate and slow chirp rate songs (Figure 2). Female mass had a significant effect on female preferences $(Z=2.10, N=40, P=0.036)$; heavier females were more likely to choose the intermediate chirp rate. Temperature also had a significant negative effect on female preferences $(Z=2.10, N=40, P=0.036)$; females tested at a higher temperature were more likely to choose the slow chirp rate. In contrast, female preferences were not significantly affected by parasitism status in the intermediate versus fast chirp rate trial; females of the two treatment groups did not significantly differ in the likelihood of choosing the fast and intermediate chirp rate songs (logistic regression: $Z=$ $0.32, N=37, P=0.752)$. Neither female mass $(Z=1.84, N=$ $37, P=0.066)$ nor ambient temperature $(Z=0.03, N=37, P=$ 0.980 ) had a significant effect on female preferences.

\section{Discussion}

The effects of parasitic infestation on female preferences are poorly understood. We tested the effect of infestation by $O$. ochracea larvae on female responsiveness to male song and female chirp rate preferences in G. lineaticeps. Responsiveness to male mating songs did not differ between infested and control females, but infested females were less choosy: while nonparasitized females preferred intermediate chirp rates to slow chirps, parasitized females did not discriminate between these two song types. This change in female preference may be beneficial for infested females and could have important effects on male song evolution.

There are a number of reasons that selection might favor plasticity in female mating preferences in response to parasitism. First, time constraints may favor reduced selectivity 


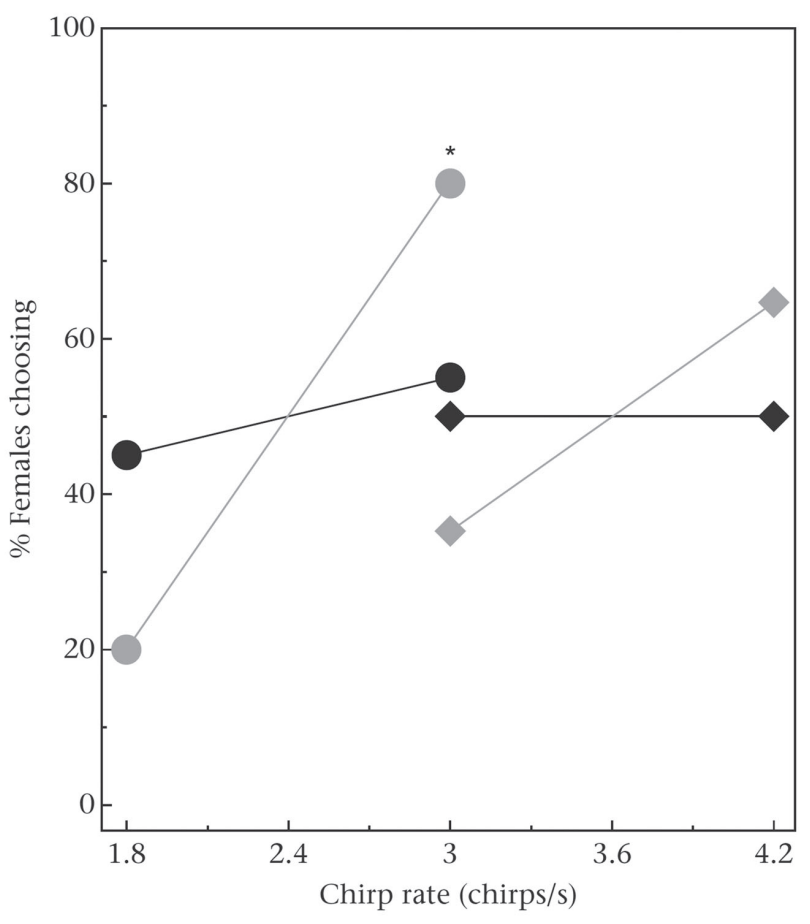

Figure 2. Percentage of infested (black lines and symbols) and control (grey lines and symbols) female field crickets, Gryllus lineaticeps, choosing each of the alternative chirp rates. Symbols indicate the percentage of females choosing a given chirp rate; lines connect female responses for a given type of choice trial (i.e. 1.8 versus 3.0 chirps/s and 3.0 versus 4.2 chirps/s). We tested the chirp rate preferences of 20 infested and 20 control females in the slow versus intermediate chirp trial, and 20 infested and 17 control females in the intermediate versus fast chirp trial. Asterisk indicates a significant difference between infested and control females in preferred chirp rate.

(Real 1990; Moore \& Moore 2001; reviewed in Jennions \& Petrie 1997). Because infested females substantially reduce oviposition after 3 days of infestation (Adamo et al. 1995b), parasitism substantially reduces the time horizon for these females to find mates and lay eggs before dying. Second, the distribution of male phenotypes within a population should affect female selectivity (reviewed in Jennions \& Petrie 1997). Because male $G$. lineaticeps are about 10 times more likely to be parasitized than females (Martin \& Wagner 2010), and because parasitoid flies, like female crickets, prefer faster chirp rates (Wagner 1996; Wagner \& Basolo 2007a, b), parasitized females are unlikely to encounter males with intermediate and high chirp rates (i.e. many of these males would also be infested and would either have stopped singing or died; Beckers \& Wagner 2011b). A parasitized female might thus use her own parasitism status as an indicator of the probability of locating males with intermediate or high chirp rates. And third, energy allocation tradeoffs should affect female investment in mate searching (Milinski \& Bakker 1992; reviewed in Jennions \& Petrie 1997). Infested females might benefit from being less choosy because reduced mate searching could allow them to save energy for processes that ameliorate the detrimental effects of infestation (e.g. immune response; Martin et al. 2003) and/or that allow them to support egg production.

Parasitized females may, however, incur costs from being less selective. In G. lineaticeps, males that produce faster chirp rates provide females with seminal fluids that increase fertility and fecundity in low nutrition environments (Wagner \& Harper 2003; Tolle \& Wagner 2011). By being less selective, parasitized females may forgo these benefits.
It is possible that the changes in female preference that we observed in G. lineaticeps may not be adaptive; rather, it might be a byproduct of larval infestation. It has been suggested that parasitic infestation in other species may cause neuronal damage that impairs the sensory or cognitive abilities necessary for discriminating between male traits (sensu Milinski 1990; Buchholz 2004). Ormia ochracea larvae inhabit the thoracic muscles in the first 3 days of infestation and do little noticeable tissue damage (Adamo et al. 1995b). Furthermore, when they leave the thoracic muscles and migrate to the abdomen approximately 3 days following infestation (Adamo et al. 1995b), they typically spare the central nervous system of the cricket (Adamo et al. 1995b). Physical damage of the nervous system may therefore not explain the difference in female preferences. However, it is possible that the mounted immune response may interfere with the host's neural system (Mallon et al. 2003) and deteriorate signal processing and thus possibly chirp discrimination. This interaction between the immune system and the nervous system could be mediated directly by chemical communication (sensu Ader et al. 1991; Pugh et al. 2001) or by a functional trade-off of shared substrates that are involved in the immune response and in nervous information processing (sensu Mallon et al. 2003).

Finally, the change in female preference of the host may be the result of manipulation by the $O$. ochracea larvae. For host manipulation to occur, the parasitoid's interests need to be different from those of the host (Milinski 1990). The larvae may interfere with the host's nervous system (through neurotransmitters), endocrine system, immune system or metabolism (Moore 2002; Beckage \& Gelman 2004; Libersat et al. 2009) to manipulate the host's behavior in its favor. According to the host manipulation hypothesis, we would predict that the larvae would reduce the mate-searching activity of the host. This reduced activity would save energy that could be stored as fat tissue, a food source for the larvae (Adamo et al. 1995b), and reduce the risk of predation and superparasitism, both of which would have negative effects on the larvae and the host (Adamo et al. 1995a; Allen 1995; Kolluru \& Zuk 2001; Welch 2006; Lehmann 2008). However, responsiveness of infested females to male song did not change, rejecting the manipulation hypothesis.

We previously discovered that noninfested female G. lineaticeps (from a nonparasitized population) express plasticity of chirp rate preferences in the context of mate assessment. Female attraction to a low, nonpreferred chirp rate $(1.8$ chirps/s; the same low rate that was used in this study) increases substantially when signalling males are scarce, which was interpreted as a possible adaptation to naturally fluctuating population densities (Beckers \& Wagner 2011b). Thus, the same mechanism underlying the adjustment of female preferences under low male density conditions (Beckers \& Wagner 2011a) may play a role for the adjustment of selectivity of infested G. lineaticeps.

The effect of parasitism on the selectivity of female G. lineaticeps parallels that found in some other species. For example, infested females of a damselfly (Cordoba-Aguilar et al. 2003), katydid (Simmons 1994), a spadefoot toad (Pfennig \& Tinsley 2002) and three fish species (Poulin 1994; Lopez 1999; male selectivity: Mazzi 2004) were less selective after infestation by a parasite. All of these results indicate that females often become less selective following parasitism, resulting in a population that consists of a mix of more selective nonparasitized females and less selective parasitized females. The flies attack G. lineaticeps only for a few weeks (Paur \& Gray 2011; W.E. Wagner, Jr., personal observation) at the end of the long mating season (Weissman et al. 1980). As a result, sexual selection on male chirp rate should fluctuate within the mating season. Selection for fast chirpers should be stronger before the flies become active and should subsequently become weaker 
due to both an increase in the proportion of less selective females and the higher mortality of fast-chirping males (see above). As a result, slow-chirping males may have greater reproductive success when flies are actively searching for hosts. Thus, parasitic infestation may help to maintain genetic and phenotypic variation for chirp rate (i.e. may help to explain the lek paradox; Borgia 1979; Taylor \& Williams 1982; Kirkpatrick \& Ryan 1991).

Acknowledgments - We thank the Basolo, Hebets and Wagner lab groups, S. Adamo and two anonymous referees for their helpful criticism and editing of the manuscript. We thank William Steinbach for assistance with the data collection. This research was supported by the National Science Foundation (IOS 0818116).

\section{References}

Adamo, S. A., Robert, D., Perez, J. \& Hoy, R. R. 1995a. The response of an insect parasitoid, Ormia ochracea (Tachinidae), to the uncertainty of larval success during infestation. Behavioral Ecology and Sociobiology 36: 111-118.

Adamo, S. A., Robert, D. \& Hoy, R. 1995b. Effects of a tachinid parasitoid, Ormia ochracea, on the behaviour and reproduction of its male and female field cricket hosts (Gryllus spp). Journal of Insect Physiology 41: 269-277.

Ader, R., Felten, D. L. \& Cohen, N. 1991. Psychoneuroimmunology. San Diego: Academic Press.

Allen, G. R. 1995. The biology of the phonotactic parasitoid, Homotrixa sp. (Diptera, Tachinidae), and its impact on the survival of male Sciarasaga quadrata (Orthoptera, Tettignoiidae) in the field. Ecological Entomology 20: 103-110.

Baudoin, M. 1975. Host castration as a parasitic strategy. Evolution 29: 335-352.

Beckage, N. E. \& Gelman, D. B. 2004. Wasp parasitoid disruption of host development: implications for new biologically based strategies for insect control. Annual Review of Entomology 49: 299-330.

Beckers, O. M. \& Wagner, W. E., Jr. 2011a. Mate sampling in a field cricket: evidence for a fixed threshold strategy with last chance option. Animal Behaviour 81: 519-527.

Beckers, O. M. \& Wagner, W. E., Jr. 2011b. Male field crickets infested by parasitoid flies express phenotypes that may benefit the parasitoids. Animal Behaviour 82: 1,151-1,157. Beckers, O. M. \& Wagner, W. E., Jr. 2012a. Divergent preferences for song structure in a field cricket and its phonotactic parasitoid. Journal of Insect Behavior 25: 467-477.

Beckers, O. M. \& Wagner, W. E., Jr. 2012b. Eavesdropping parasitoids do not cause the evolution of less conspicuous signalling behaviour in a field cricket. Animal Behaviour 84: 1,457-1,462.

Borgia, G. 1979. Sexual selection and the evolution of mating systems. In: Sexual Selection and Reproductive Competition in Insects (Ed. by M.S. \& N.A. Blum), pp. 19-80. New York: Academic Press.

Buchholz, R. 2004. Effects of parasitic infection on mate sampling by female wild turkeys (Meleagris gallopavo): should infected females be more or less choosy? Behavioral Ecology 15: 687-694.

Cade, W. 1975. Acoustically orienting parasitoids: fly phonotaxis to cricket song. Science 190: 1,312-1,313.

Chaine, A. S. \& Lyon, B. E. 2008. Adaptive plasticity in female mate choice dampens sexual selection on male ornaments in the lark bunting. Science 319: 459-462.
Cordoba-Aguilar, A., Salamanca-Ocana, J. C. \& Lopezaraiza, M. 2003. Female reproductive decision and parasite burden in a calopterygid damselfly (Insecta: Odonata). Animal Behaviour 66: 81-87.

Cotton, S., Small, J. \& Pomiankowski, A. 2006. Sexual selection and condition-dependent mate preferences. Current Biology 16: 755-765.

van Dijken, M. J. \& Waage, J. K. 1987. Self and conspecific superparasitism by the egg parasitoid Trichogramma evanescens. Entomologia Experimentalis et Applicata 43: 183-192.

Godin, J. G. \& Briggs, S. E. 1995. Female mate choice under predation risk in the guppy. Animal Behaviour 51: 117-130.

Gong, A. \& Gibson, R. M. 1996. Reversal of a female preference after visual exposure to a predator in the guppy, Poecilia reticulata. Animal Behaviour 52: 1,007-1,015.

Hebets, E. A. 2003. Subadult experience influences adult mate choice in an arthropod: exposed female wolf spiders prefer males of a familiar phenotype. Proceedings of the National Academy of Sciences, U.S.A. 100: 13,390-13,395.

Hedrick, A. V. \& Dill, L. M. 1993. Mate choice by female crickets is influenced by predation risk. Animal Behaviour 46: 193-196.

Jennions, M. D. \& Petrie, M. 1997. Variation on mate choice and mating preferences: a review of causes and consequences. Biological Reviews 72: 283-327.

Johnson, J. B. \& Basolo, A. L. 2003. Visual exposure to a natural predator changes female preference for conspicuous male ornaments in the green swordtail. Behavioral Ecology 14: 619-625.

King, A. P., West, M. J. \& White, D. J. 2003. Female cowbird song perception: evidence for plasticity of preference. Ethology 109: 865-877.

Kirkpatrick, M. \& Ryan, M. J. 1991. The paradox of the lek and the evolution of mating preferences. Nature 350: 33-38.

Kolluru, G. R. \& Zuk, M. 2001. Parasitism patterns and the sizeefecundity relationship in the acoustically orienting dipteran parasitoid Ormia ochracea. Canadian Journal of $\mathrm{Zo}-$ ology 79: 973-979.

Lehmann, G. U. 2008. How different host species influence parasitism patterns and larval competition of acousticallyorienting parasitoid flies (Tachinidae: Ormiini). In: Animal Behavior: New Research (Ed. by E. A. Weber \& L. H. Krause), pp. 93-132. Hauppauge: Nova Science.

Libersat, F., Delago, A. \& Gal, R. 2009. Manipulation of host behavior by parasitic insects and insect parasites. Annual Review of Entomology 54: 189-207.

Lopez, S. 1999. Parasitized female guppies do not prefer showy males. Animal Behaviour 57: 1,129-1,134.

Mallon, E. B., Brockmann, A. \& Schmid-Hempel, P. 2003. Immune response inhibits associative learning in insects. Proceedings of the Royal Society B 270: 2,471-2,473.

Martin, C. M. \& Wagner, W. E., Jr. 2010. Female field crickets incur increased parasitism risk when near preferred song. PLoS One 5: e9592.

Martin, L. B., II, Scheuerlein, A. \& Wikelski, M. 2003. Immune activity elevates energy expenditure of house sparrows: a link between direct and indirect costs? Proceedings of the Royal Society B 270: 153-158.

Mazzi, D. 2004. Parasites make male pipefish careless. Journal of Evolutionary Biology 17: 519-527. 
Milinski, M. 1990. Parasites and host decision-making. In: Parasitism and Host Behaviour (Ed. by C. J. Barnard \& J. M. Behnke), pp. 95-116. London: Taylor \& Francis.

Milinski, M. \& Bakker, T. C. M. 1992. Costs influence sequential mate choice in stickleback, Gasterosteus aculeatus. Proceedings of the Royal Society B 250: 229-233.

Moore, J. 1995. The behavior of parasitized animals. Bioscience 45: 89-96.

Moore, J. 2002. Parasites and the Behavior of Animals. Oxford: Oxford University Press.

Moore, P. J. \& Moore, A. J. 2001. Reproductive aging and mating: the ticking of the biological clock in female cockroaches. Proceedings of the National Academy of Sciences, U.S.A. 98: 9,171-9,176.

Murray, A. M. \& Cade, W. H. 1995. Differences in age structure among field cricket populations (Orthoptera: Gryllidae): possible influence of a sex-biased parasitoid. Canadian Journal of Zoology 73: 1,207-1,213.

Paur, J. \& Gray, D. A. 2011. Seasonal dynamics and overwintering strategy of the tachinid fly (Diptera: Tachinidae), Ormia ochracea (Bigot) in southern California. Terrestrial Arthropod Reviews 4: 145-156.

Pfennig, K. S. \& Tinsley, R. C. 2002. Different mate preferences by parasitized and unparasitized females potentially reduces sexual selection. Journal of Evolutionary Biology 15: 399-406.

Poulin, R. 1994. Mate choice decisions by parasitized female upland bullies, Gobiomorphus breviceps. Proceedings of the Royal Society B 256: 183-187.

Poulin, R. \& Vickery, W. L. 1996. Parasite-mediated sexual selection: just how choosy are parasitized females? Behavioral Ecology 38: 43-49.

Pugh, C. R., Fleshner, M., Watkins, L. R., Maier, S. F. \& Rudy, J. W. 2001. The immune system and memory consolidation: a role for the cytokine IL-1b. Neuroscience and Biobehavioral Reviews 25: 29-41.

Real, L. A. 1990. Search theory and mate choice. I. Models of single-sex discrimination. American Naturalist 136: 376-404.

Ritchie, L. E. \& Høeg, J. T. 1981. The life history of Lernaeodiscus porcellanae (Cirripedia: Rhizocephala) and co-evolution with its porcellanid host. Journal of Crustacean Biology 1: 334-347.

Rolff, J. 1998. Parasite-mediated sexual selection: parasitized non-choosy females do not slow down the process. Behavioral Ecology and Sociobiology 44: 73-74.

Rupp, J. C. 1996. Parasite-altered behavior: impact of infection and starvation on mating in Biomphalaria glabrata. Parasitology 113: 357-365.

Simmons, L. W. 1994. Courtship role reversal in bush crickets: another role for parasites? Behavioral Ecology 5: 259-266.
Taylor, P. D. \& Williams, G. C. 1982. The lek paradox is not resolved. Theoretical Population Biology 22: 392-409.

Tolle, A. E. \& Wagner, W. E., Jr. 2011. Costly signals in a field cricket can indicate high- or low-quality direct benefits depending upon the environment. Evolution 65: 283-294.

Vincent, C. M. \& Bertram, S. M. 2009. Collection and laboratory culture of Ormia ochracea (Diptera: Tachinidae). Journal of Entomological Science 45: 1-7.

Wagner, W. E., Jr. 1996. Convergent song preferences between female field crickets and acoustically orienting parasitoid flies. Behavioral Ecology 7: 279-285.

Wagner, W. E., Jr. \& Basolo, A. L. 2007a. The relative importance of different direct benefits in the mate choices of a field cricket. Evolution 61: 617-622.

Wagner, W. E., Jr. \& Basolo, A. L. 2007b. Host preferences in a phonotactic parasitoid of field crickets: the relative importance of host song characters. Ecological Entomology 32: 478-484.

Wagner, W. E., Jr. \& Harper, C. J. 2003. Female life span and fertility are increased by the ejaculates of preferred males. Evolution 57: 2,054-2,066.

Wagner, W. E., Jr. \& Reiser, M. G. 2000. The relative importance of calling song and courtship song in female mate choice in the variable field cricket. Animal Behaviour 59: 1,219-1,226.

Wagner, W. E., Jr., Kelley, R. J., Tucker, K. R. \& Harper, C. J. 2001a. Females receive a lifespan benefit from male ejaculates in a field cricket. Evolution 55: 994-1,001.

Wagner, W. E., Jr., Smeds, M. R. \& Wiegmann, D. D. 2001b. Experience affects female responses to male song in the variable field cricket Gryllus lineaticeps (Orthoptera, Gryllidae). Ethology 107: 769-776.

Wagner, W. E., Jr., Smith, A. R. \& Basolo, A. L. 2007. False promises: females spurn cheating males in a field cricket. Biology Letters 3: 379-381.

Weissman, D. B., Rentz, D., Alexander, R. D. \& Loher, W. 1980. Field crickets (Gryllus and Acheta) of California and Baja California, Mexico (Orthoptera: Gryllidae: Gryllinae). Transactions of the American Entomological Society 106: 327-356.

Welch, C. H. 2006. Intraspecific competition for resources by Ormia depleta (Diptera: Tachinidae) larvae. Florida Entomologist 89: 497-501.

Zakikhani, M. \& Rau, M. E. 1999. Plagiorchis elegans (Digenea: Plagiorchiidae) infections in Stagnicola elodes (Pulmonata: Lymnaeidae): host susceptibility, growth, reproduction, mortality, and cercarial production. Journal of Parasitology 85: 454-463.

Zuk, M., Thornhill, R., Ligon, J. D. \& Johnson, K. 1990. Parasites and mate choice in red jungle fowl. American Zoologist 30: 235-244. 